reality of a Maori community sufficiently organized to assert direct influence on the development of social policy" (p. 184). Despite this positive assertion, however, Armitage earlier states that, 'the policies of integration established in the 1960 s... remain in effect in the day-to-day operation of New Zealand social and educational services“(p. 159). Integration is differentiated from assimilation (pp. 142-146) which raises broader questions about the scope and focus of the whole work.

The last two chapters represent a comparative analysis of the three study areas. In comparing the "similarities and differences" the author selects six issues for attention: social policy, labeling of indigenous peoples, instruments of government policy, separation of children, regional and demographic differences, and recovery of indigenous peoples. The main instruments for comparison are tables that set out comparative data but introduce novel policy period definitions ("Paternalism: Protection;" "Paternalism: Assimilation;" "Integration" and "Pluralist"). This is puzzling in the light of the previous chapters where such categories are more or less absent. At the beginning of the last chapter, Armitage states, "it has been shown that Australia, Canada and New Zealand had, in common, a general policy of aboriginal assimilation" (p. 220). The chapter then goes on to "understand aboriginal assimilation" by looking at trace relations, colonialism, ethno nationalism and social policy. Although the descriptive accounts of the four issues are adequate, it is difficult to see exactly where the analysis is going except to some general conclusions about the nature of colonialism and the powerless state of indigenous peoples when their land is appropriated.

This book's major contribution is to provide a summary of the history of government policies in the three countries and a potted overview of the events of colonization. As a comparison of policies, however, it lacks the focus and definition of a work that identifies the major issues and brings them to a compelling comparison. This is, for the most part, a consequence of a failure to clearly define the policy terms. The author has conflated "assimilation" with the context of a whole range of other issues and policies from which it is in fact distinct. It is rather as if the author sees "assimilation" as a matter of colonialism and exploitation, a generic terms that encapsulates the history of indigenous peoples in three countries. Clearly, the situation is not as simple as that. The result is that tough issues and complex policy strands are ignored or become lost in generalizations and summary statements.

\title{
Social Ecology, Edited by Ramchandra Guha; Oxford in India Readings in Sociology and Social Anthropology. Delhi: Oxford University Press. 1994. x,398 pp.
}

\author{
Reviewed by Satadal Dasgupta Department of Sociology and \\ Anthropology, University of Prince Edward Island.
}

Social Ecology is a collection of sixteen papers on social ecology in India, all but one of which are excerpts from previously published sources. In a crisply written introduction to the volume, editor Guha points out the increasing public concern for the various forms of environmental degradation in India. Guha observes that while natural scientists as well 
as environmental journalists and activists have made significant contributions to the understanding of social implications of environmental degradation, the "environmental crisis has caught the social science community unawares" even though it is "well within the purview of social sciences" (p.2). He argues, perhaps correctly, that any concern with ecological variables in India has been viewed as irresponsible and as an irrelevant constraint to the urgent efforts for development because of the emphasis on rapid industrialization and development after independence from British rule in 1947 and the consequent intellectual domination of economics.

Guha argues in favor of creating an "environmentally oriented sociology" and suggests that the inclusion of "ecological infrastructure" at the base of the four existing broad categories of sociologists' "model of society"-- economy, social structure, polity, and culture, arranged in a pyramidal fashion -- will not only incorporate ecology in the theory of society but will also allow an examination of its reciprocal relations with the four major societal elements. The four sectional themes used to organize the sixteen papers are presumably based on this model of environmentally oriented sociology, each section indicating one of several directions the study of social ecology might take in India.

The five papers included in the first section, 'Nature and Culture,' focus on the close interdependence among nature, society, and culture. The section starts with a paper by Radhakamal Mukherjee, one of India's revered pioneers in sociology who pointed out as early as 1930, when the paper was originally published, the interactive and dynamic relationships between nature and culture. In another interesting paper, M. Gadgil and K.C. Malhotra show how nine different castes in the western region of the Maharashtra state have coexisted for generations adapting to specific niches of their environment. The effects of environment on the social structure and culture are further demonstrated by J. Mencher who shows how the differences in settlement patterns and authority and caste structures between two southern states, Kerala and Madras (now Tamilnadu), can be explained in terms of differences in the intensity of monsoon rains, water tables, and other natural features. The final two papers of the section, by M. Gadgil and V.D. Vartak and by M. Dove respectively, deal with the sacred uses of nature and their implications for conservation and the dialectical relation between nature and culture as evident in the natives' view of the "jungle."

The second and longest section, 'The Sociology of Resource Use and Abuse,' includes six papers dealing with, as the title of the section indicates, use and abuse of four major natural resources --water, forest, pastures, and fisheries -- and their implications for social structure. The first two papers examine how use of water affects social structure: R. Mukherjee's paper argues that use of water as a scarce resource contributes to certain specific types of community organizations; N. Sengupta's paper draws attention to the social relations that emerge based on irrigation works. The paper by E. Whitcombe has, as the editor points out, "a markedly contemporary ring" in that it shows the negative consequences of the canal systems built during the British period in northern India. Although they contributed to higher productivity and income as farmers shifted to the cultivation of cash crops, the large canal systems also brought water salinity, water logging, and spread of malaria. The last three papers of the section deal with the use of common property resources: the first two, by N.S. Jodha and by V. Vidyarthi, discuss the importance of common property resources to rural economy and the negative consequences of their depletion for the rural poor. The last paper by J. Kurien and T.K. Thankappan Achari deals with the disastrous effects of large trawlers on fishermen using the traditional artisanal craft. 
Competition for resources among different groups is further illustrated in the three papers included in the third section: 'Competing Claims Over Nature.' Excerpts from V. Elwin's (1939) classic ethnography The Baiga of Central India, for example, describe how British colonial officials' establishment of commercial forestry and effort to wean the tribe away from "inferior" shifting cultivation caused irreparable damage to the Baiga economy and culture. The second paper, authored by the editor of the volume, describes a similar conflict between the state forestry and local peasants in the Kumaun region to whom access to forests and pastures was crucial for their economic activities. In the last paper, written especially for the volume, R. Sukumar provides a highly interesting analysis of the conflict between wild life and humans competing for the same natural resources.

The final section of the volume, 'Towards an Environmental Renewal,' includes only two papers, both of which, according to the words of the editor, are "at once reflective and programmatic" and offer diagnoses of "the social processes behind ecological degradation even as they outline the elements of an environmentally benign, and socially humane, strategy of development" (p.319). In his paper, A.K.N. Reddy cautions against injudicious adoption and application of modern technology by developing countries without first assessing their effects on the natural environment and the existing sociocultural conditions. A. Agarwal in the last paper also illustrates the connection between intensification of resource use through modern technology and environmental degradation and poverty.

The volume, meant primarily for use by students, will no doubt serve as an excellent text for a course on social ecology. As the first such volume of readings on social ecology in India, the book indeed provides a "compact and analytically sophisticated overview "of the field, as claimed on the jacket. The publishers must be congratulated for the Oxford in India Readings in Sociology and Social Anthropology series, not only for the superior quality of the volumes published so far, but also for their careful printing and fine production.

\section{Land in African Agrarian Systems. Thomas J. Bassett and Donald E. Crummey, editors. Madison, WI. and London: University of Wisconsin Press. 1993. xi, 418 pp.}

\section{Reviewed by Stephen P. Reyna, Professor and Chair of Anthropology, University of New Hampshire, Durham.}

The University of Illinois, Urbana-Champaign, during its Center for African Studies 1988 spring symposium, considered the topic of land in African agrarian systems. The resulting volume, Land in African Agrarian Systems, includes an introduction and thirteen papers analyzing African land tenure in the 1970s and 1980s. Below I give readers some appreciation of the substance of these papers and of a research priority that they suggest.

The volume is divided into three sections: one addressing questions of flexibility and conflict in indigenous landholding systems, another concerning access to land and agrarian politics, and a third considering agricultural performance under conditions of 